\title{
Peningkatan Kinerja Koperasi dan UKM Melalui Kemitraan Usaha
}

\author{
Muh. Yunus
}

Penulis adalah Dosen Fakultas Tarbiyah UIN Malang

\begin{abstract}
Since economically Indonesia decline because of monetary crisis in 1997, "partnership" program considered as the alternative to solve economic problem of Cooperatives and Small and Medium Enterprises (SMEs). Its importance to decrease cost and improve production quality, to avoid supply/demand fluctuation, to create external scale of economies, to avoid uncertainty and to guaranty of good and service flow by continuously. The partnership program can be efficient, when there is no unbalance relationship conditions among Cooperatives/SMEs with their partner: Cooperatives/ SMEs in "worse of" conditions and partners in "better of" condition. So, the performance of Cooperatives/SMEs can be improved.

So far, the measurement of cooperative performance focusing on finance aspect. The firm reaches high Rol considered as success-full business. Where as, measuring business performance only on financial aspect can be bias. Therefore, it is importance to have new approach on measurement business performance using "Balanced Scorecard".
\end{abstract}

Ulul Albab, Vol. 4 No. 1, 2003 


\section{Latar Belakang}

Keterkaitan usaha atau kemitraan usaha antara Koperasi, BUMN, dan swasta sudah merupakan tekad nasional dalam rangka pembangunan ekonomi Indonesia, terutama dalam jangka panjang diharapkan dapat mengantarkan kepada tercapainya struktur ekonomi yang seimbang. Oleh karena itu, sejak tanggal 14 Januari 1991 pemerintah telah mencanangkan program kemitraan yang kemudian diperkuat dengan diberlakukannya Undang Undang Nomor 9 Tahun 1995 Tentang Usaha Kecil serta Peraturan Pemerintah (PP) Nomor 44 Tahun 1997 Tentang Kemitraan.

Sejak Indonesia terpuruk secara ekonomi karena terpaan badai krisis moneter pada tahun 1997, program kemitraan dianggap sebagai pilihan bijak dalam mengatasi masalah perekonomian rakyat. Menurut PPNo. 44 Tahun 1997 Tentang Kemitraan, "Kemitraan" didefinisikan sebagai kerjasama usaha antara Usaha Kecil dengan Usaha Menengah dan atau dengan Usaha Besar disertai pembinaan dan pengembangan oleh Usaha Menegah dan atau Usaha Besar dengan memperhatikan prinsip-prinsip saling memerlukan, saling memperkuat dan saling menguntungkan" (PP No.4 Tahun 1997 Pasal 1).

Sebagai salah satu pelaku ekonomi, kehadiran koperasi diharapkan dapat menjadi tulang punggung perekonomian nasional. Sebagai gambaran, di propinsi Jawa Barat yang penduduknya terpadat di pulau Jawa, terdapat sekitar 15.000-an koperasi. Berdasarkan sensus terhadap koperasi yang tersebar di wilayah itu, secara kuantitatif dari tahun ke tahun terlihat jumlah koperasi terus meningkat. Hingga tahun 2001 , tercatat sejumlah 14.396 koperasi, meningkat sebesar $11,66 \%$ dari tahun 2000 yang berjumlah 12.893 koperasi. Kontribusi koperasi terhadap PDRB Jawa Barat tahun 2000 hanya 0,51\% (Rp 704.947 juta dari Rp 137.428.287,97 juta). Pada tahun 2001 meningkat kontribusinya menjadi 1,20\% (BPS Jawa Barat dalam Sutyastie, 2002: 2).

Meskipun ada gambaran peningkatan, tetapi masih tergolong sangat kecil bila dibandingankan dengan kontribusiBadan Usaha Milik Negara(BUMN) maupun Badan Usaha Milik Swasta (BUMS) terhadap perekonomian nasional. Demikian pula dari segi pemasaran, dari hasil penelitiannya teridentifikasi hanya ada 15 buah koperasi yang berhasil menembus pasaran internasional di wilayah itu. Dari jumlah tersebut, terdapat tiga koperasi di Kabupaten Cianjur dan dua koperasi di Kabupaten 
Bandung yang mendominasi pemasaran internasional. Sedangkan sebagian besar yang lain (95,62\%), masih “jago kandang" (2002: 44).

Melihat fenomena tersebut, Herman Soewardi (1995: 109) menggambarkannya dengan istilah Static Expansion, artinya sebagian besar pertumbuhan koperasi masih bersifat kuantitatif yang tidak disertai dengan kemajuan secara kualitatif. Oleh karena itu, Remitjahari mengidentifikasi lima masalah pokok dan sekaligus sebagai acuan program penanggulangannya, yaitu: rendahnya kualitas sumber daya manusia, lemahnya akses terhadap teknologi, lemahnya permodalan dan akses terhadap sumber permodalan, lemahnya akses terhadap pasar, dan lemahnya akses terhadap informasi (Remitjahari, 2002: 5-6). Melalui program kemitraan, diharapkan kelemahan-kelemahan itu dapat diatasi sehingga koperasikoperasi dan Usaha Kecil Menegah (UKM) memiliki daya saing yang tinggi dalam menghadapi era perdagangan bebas.

\section{Manfaat Strategis Kemitraan}

Untuk mengembangkan koperasi dan UKM, salah satu pendekatan yang dapat digunakan adalah mengembangkan jaringan usaha antara usaha besar, menengah dan kecil, baik koperasi, BUMN, maupun swasta agar dapat saling mengisi secara sinergis (Wagiono, 1992). Keterkaitan dengan BUMN misalnya, akan diperoleh bantuan seperti: pelatihan kewirausahaan, manajemen produksi dan pemasaran; pinjaman modal kerja dengan bunga rendah; keikutsertaan dalam perusahaan modal ventura, dan lain sebagainya (Hiro Tugiman, 1995: 18). Sedangkan pendekatannya dapat dilakukan antara lain melalui: konsultasi dan bantuan teknis, akses pendanaan usaha dan pemagangan (Soeharsono, 1996: 133134).

Sejalan dengan pandangan tentang perlunya kerja sama dalam persaingan pasar yang tajam, Yuyun Wirasasmita (2000) dan tulisan lainnya dalam Rusidi dan Maman Suratman (2002: 189-120) menawarkan konsep penemuan kembali (Reinventing) kaidah manajemen strategis koperasi yang bertumpu pada efisiensi (biaya rendah) dan keunikan produk melalui delapan butir alternatif kebijakan restrukturisasi, empat diantaranya yang relevan dengan masalah ini yaitu: pertama, mendorong koperasi tunggal usaha dengan core business yang layak. Sebab 
koperasi tunggal (single purpose) dengan multicommodity sebagai upaya untuk mengurangi biaya rendah; kedua, mendorong merger agar tercapai minimum efficient size; ketiga, kriteria anggota sebagai pemilik dan pelanggan dengan konteks hubungan kontraktual. Hubungan kontraktual ini akan mengurangi ketidakpastian yang pada gilirannya dapat menekan biaya-biaya organisasi dan produksi; dan keempat, mendorong kemitraan atau aliansi strategik.

Tujuan kerjasama melalui kemitraan antara pengusaha besardengan koperasi, menurut hasil penelitian Anton (1996: 41) antara lain adalah untuk meningkatkan kualitas dan kuantitas hasil, memperpendek mata rantai pemasaran yang pada akhirnya dapat meningkatkan pendapatan. Agar tujuan tersebut tercapai, Muryati Sudibyo (1997: 33) mengemukakan bahwa keduanya harus berpartisipasi aktif dua arah, ada partisipasi pengusaha besar, juga pengusaha kecil. Hal itu juga didukung oleh Yuanita Indriani (1994: 47) yang salah satu hasil penelitiannya merekomendasikan bahwa pola kemitrausahaan yang berhasil itu sayogyanya dijalankan dengan pola dagang yang mengikuti trik bisnis modern. Adapun model kemitraannya menurut Alexander Irwan (1997: 19) dapat berupa Keiretsu, Sogoshosha, ventura atau lainnya.

Dipandang dari kacamata ekonomi, keterkaitan itu dirasa perlu untuk menurunkan biaya dan meningkatkan kualitas produksi, mencegah fluktuasi supply/ demand (Prawirokusumo dalam Thee Kian Wie, 1992: 121). Hal ini mempunyai dua jenis dampak positip, yaitu menciptakan external scale of economies" dan mengurangi ketidakpastian. Keduanya dapat berpengaruh pada penurunan biaya, sebab melalui kemitraan dapat memperluas pemasokan barang-barang yang dibutuhkan koperasi, sekaligus menjamin aliran barang secara teratur.

Secara teoretik, hubungan kemitraan tersebut dapat disebut efisien, apabila tidak ada kondisi yang menyebabkan badan usaha koperasi merasa better off di satu pihak, dan mitrausahanya merasa worse off di pihak lain (Varian, Hal R. 1999: 511). Oleh karena itu, kemitraan itu sebaiknya didasarkan atas prinsip saling menguatkan, saling memerlukan dan saling menguntungkan kedua belah pihak. 


\section{Pengukuran Kinerja Koperasi}

Pengukuran kinerja merupakan salah satu faktor yang penting dilakukan oleh perusahaan, termasuk badan usaha berbentuk koperasi. Selama ini, pengukuran kinerja secara konvensional lebih menitikberatkan pada aspek finasial. Badan usaha yang mencapai Return on Invesment yang tinggi akan dinilai berhasil, dan manajernya memperoleh imbalan yang tinggi dari perusahaannya.

Menurut Felix Jebarus, istilah kinerja atau perfomance seringkali dikaitkan dengan kondisi keuangan perusahaan. Tradisi konvensional yang berlaku selama ini, pengukuran kerja suatu perusahaan didasarkan pada tingkat pengembalian perusahaan (Return on Invenstment/ROI, Return on Equity/ROE, dan Profit Margin) (1997: 68). Selanjutnya, ukuran kinerja dianalisis dalam tiga kelompok, yaitu: rasio profitabilitas, mengukur efektifitas manajemen berdasarkan hasil pengembalian dari hasil penjualan dan investasi; rasio pertumbuhan, mengukur kemampuan perusahaandalam pertumbuhan ekonomi dan industri atau pasar produk tempat beroperasi; dan ukuran penilaian, mengukur kemampuan manajemen untuk mencapai nilai-nilai pasar yang melebihi pengeluaran kas (Weston dan Thomas (1995: 237).

Akan tetapi, menilai kinerja sebuah perusahaan semata-mata dari keberhasilan aspek keuangan dapat menyesatkan. Sebabnya antara lain banyak intangible asset yang tak terukur itu lepas dari penilaian perusahaan. Untuk mengatasi hal ini, ada pendekatan baru yang mencoba mengukur kinerja perusahaan dengan menyeimbangkan pengukuran aspek keuangan dan non keuangan yang disebut dengan Balanced Scorecard. Terdapat empat perspektif dalam pengukuran kinerja perusahaan berdasarkan pendekatan Balanced Scorecard, yaitu: perspektif keuangan, pelanggan, proses bisnis internal, serta proses belajar dan berkembang (Kaplan dan Norton, 1996: 44).

Penerapan pengukuran keberhasilan dengan menggunakan. Balanced Scorecard, selama ini lebih sering diperuntukkan pada perusahaan dengan motif mencari laba (profit seeking organizations). Masih jarang sekali ada pembahasan mengenai penerapan Balanced Scorecard pada organisasi nirlaba (not profit organizations) atau organisasi dengan karakteristik khusus seperti koperasi, yang ditandai dẹngan relational contracting, yakni saat owner dan customer adalah 
orang sama, serta mutual benefit anggota menjadi prioritasnya (Merchant, 1998; dalam Ali Mutasowifin, 2002:246).

Badan usaha koperasi pada dasarnya bukanlah organísasi persekutuan modal, tetapi lebih merupakan persekutuan orang. Apabila koperasi diukur dari aspek keuangannya semata, maka gambaran kinerja koperasi secara utuh tak tertangkap, banyak aktivitas yang potensial dapat menciptakan nilai (value creating avtivities) dari aktiva-aktiva tak berwujud tidak dipertimbangan. Padahal, menurut Ali Mutasowifin (2002: 246) pada era kompetisi yang berbasis pengetahuan (knowledge based competition), memelihara dan memobilisasi aktiva tak berwujud (intangible assets) yang dimiliki merupakan kunci keberhasilan.

Tolak ukur kinerja mencerminkan keputusan-keputusan strategis, operasi dan pembiayaan. Dari tolak ukur ini, maka perusahaan-perusahaan yang mengharapkan kemampuan persaingan di masa datang, pihak manajemen perusahaan perlu mengukur kinerja bisnis mereka (Soetjipto, 1997: 21. Namun ukuran kinerja keuangan memiliki kelemahan, yaitu tidak mampu mengukur assetasset yang sebenarnya sangat penting tetapi bersifat intangible, seperti ketrampilan, kompetensi, dan motivasi pegawai, database dan teknologi informasi, inovasi dalam produk dan jasa, kesetiaan pelanggan, dukungan politis, peraturan perundangundangan dan dari masyarakat (Kaplan dan Norton, 2000) dalam Ali Mutasowwifin (2002: 246). Demikian pula hasil pengukuran kinerja keuangan tidak mampu mengenal masa lalu perusahaan dan tak mampu menuntun perusahaan ke arah yang lebih baik (Kaplan dan Norton, dalam Soetjipto, 1997:21). Untuk itu, keduanya menyarankan pengukuran kinerja bisnis melalui Balance Scorcad (BSC) yang diciptakannya. BSC tidak saja mengukur hasil akhir (outcome), tetapi juga aktivitasaktivitas penentu akhir (driver). Secara umum, terdapat empat macam kinerja bisnis yang diukur melalui BSC, yaitu: (1) keuangan, dalam hal posisi perusahaan di daur bisnis, (2) pelanggan, (3) proses internal, dan (4) pembelajaran dan pertumbuhan.

Berikut ini, Ali Mutasowifin (2002: 260-261) mengajukan beberapa ukuran berdasarkan pendekatan Balanced Scorecard dengan strategi pertumbuhan yang diperuntukkan bagi koperasi sebagaimana tampak pada sbb: 


\section{Perspektif Keanggotaan}

\begin{tabular}{|c|c|c|}
\hline Tujuan Strategis & Ukuran Hasil Utama & Ukuran Pendorong Kinerja \\
\hline $\begin{array}{l}\text { Kualitas } \\
\text { Kehidupan }\end{array}$ & $\begin{array}{l}\text { Peningkatan persentase } \\
\text { kesejahteraan anggota }\end{array}$ & $\begin{array}{l}\text { - Kemampuan daya beli pelang- } \\
\text { gaṇ/anggota terhadap koperasi }\end{array}$ \\
\hline Pelayanan & $\begin{array}{l}\text { - Persentase penjualan } \\
\text { pro-duk dari atau } \\
\text { untuk ang-gota } \\
\text { - Retensi anggota }\end{array}$ & $\begin{array}{l}\text { - Pemenuhan kebutuhan anggota } \\
\text { oleh koperasi } \\
\text { - Survey kepuasan anggota terha- } \\
\text { dap produk dan layanan }\end{array}$ \\
\hline $\begin{array}{l}\text { Meningkatkan } \\
\text { SHU }\end{array}$ & 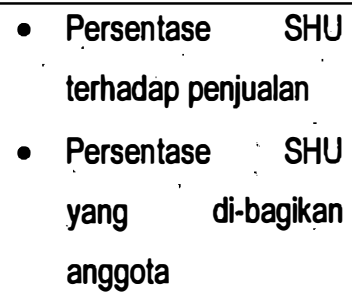 & $\begin{array}{l}\text { - Manfaat ekonomi langsung } \\
\text { - Manfaat ekonomi tak langsung }\end{array}$ \\
\hline
\end{tabular}

\section{Perspektif Keuangan}

\begin{tabular}{|l|l|l|l|}
\hline \hline Tujuan Strategis & Ukuran Hasil Utama & & Ukuran Pendorong Kinerja \\
\hline Meningkatkan & Perhitungan Nilai Tambah & & \\
Nilai Tambah & Ekonomis yang diperoleh & & \\
\hline Meningkatkan & Persentase peningkatan & Jumlah produk yang dipasok anggota \\
Pendapatan & pen-dapatan anggota & & \\
Anggota & $\ddots$ & & \\
\hline Pertumbuhan & Persentase peningkatan & & \\
Pendapatan & pen-dapatan koperasi & & \\
\hline
\end{tabular}


Perspektif Proses Bisnis Internal

\begin{tabular}{|c|c|c|}
\hline Tujuan Strategis & Ukuran Hasil Utama & Ukuran Pendorong Kinerja \\
\hline $\begin{array}{l}\text { Memaksimalkan } \\
\text { produktifitas }\end{array}$ & & $\begin{array}{l}\text { Anggota yang terlayani } \\
\text { per karyawan }\end{array}$ \\
\hline $\begin{array}{l}\text { Meningkatkan } \\
\text { kualitas informasi } \\
\text { tentang } \\
\text { keanggotaan }\end{array}$ & & $\begin{array}{l}\text { - Ketersediaan informasi potensi } \\
\text { ekonomi anggota } \\
\text { - Ketersediaan kebutuhan ekonomi } \\
\text { anggota }\end{array}$ \\
\hline $\begin{array}{l}\text { Meningkatkan } \\
\text { interaksi dengan } \\
\text { ang-gota dan } \\
\text { masyarakat }\end{array}$ & $\begin{array}{l}\text { - Persentase anggota } \\
\text { yang aktif berpar- } \\
\text { tisipasi } \\
\text { - Persentase } \\
\text { masyarakat yang } \\
\text { aktif berpartisipasi }\end{array}$ & $\begin{array}{l}\text { - Waktu bersama anggota } \\
\text { - Waktu bersama masyarakat }\end{array}$ \\
\hline
\end{tabular}

Perspektif Proses Pembelajaran dan Pertumbuhan

\begin{tabular}{|c|c|c|}
\hline Tujuan Strategis & Ukuran Hasil Utama & Ukuran Pendorong Kinerja \\
\hline $\begin{array}{l}\text { Meningkatkan } \\
\text { kompetensi } \\
\text { karyawan }\end{array}$ & Produktifitas karyawan & $\begin{array}{l}\text { Pengembangan karyawan } \\
\text { vs rencana }\end{array}$ \\
\hline $\begin{array}{l}\text { Mengembangkan } \\
\text { sistem informasi } \\
\text { strategis }\end{array}$ & & $\begin{array}{l}\text { Rasio ketersediaan infor-masi strategis } \\
\text { vs rencana }\end{array}$ \\
\hline $\begin{array}{l}\text { Menggalakkan } \\
\text { pendidikan } \\
\text { perkoperasian }\end{array}$ & $\begin{array}{l}\text { - Persentase jumlah } \\
\text { anggota baru }\end{array}$ & $\begin{array}{l}\text { - Frekwensi penyelenggaraan } \\
\text { pendidikan perkoperasian } \\
\text { - Survey keberterimaan koperasi } \\
\text { oleh masyarakat }\end{array}$ \\
\hline
\end{tabular}

Sumber: Ali Mutasowifin (2002: 261).

Ulul Albab, Vol. 4 No. 1, 2003 


\section{Catatan Akhir}

Secara normatif, melalui hubungan kemitraan diharapkan akan dapat menciptakan nilai tambah, efisiensi dan produktifitas usaha bagi kedua belah pihak dan selanjutnya akan memperkokoh ekonomi dan industri nasional. Selain itu, juga diharapkan terjadi alih pengetahuan, keterampilan penguasaan teknik-teknik manajemen usaha dan teknologi proses yang pada gilirannya nanti dapat meningkatkan kinerja koperasi dan UKM.

Meskipun demikian, dari serangkaian pola kemitraan antara BUMN, BUMS dan Koperasi termasuk UKM yang berjalan selama ini, belum diperoleh data yang cukup meyakinkan bahwa serangkaian pola kemitraan yang diterapkan tersebut berjalan baik seperti yang diharapkan, yakni dapat meningkatkan kinerja kedua belah pihak atas dasar prinsip saling memerlukan, saling memperkuat dan saling menguntungkan.

Persoalan tersebut perlu diteliti lebih lanjut, sebab semangat UUD' 45 terutama pasal 33 pada dasarnya mengarah pada terwujudnya struktur ekonomi yang tangguh dan berkeadilan. Untuk itu, peranan pemerintah, lembaga-lembaga swadaya masyarakat (LSM), perguruan-perguruan tinggi dan dunia usaha, terutama UKM dan koperasinya itu sendiri, perlu terus berusaha meningkatkan kinerjanya. Kemitraan, hanyalah salah usaha untukitu. Tetapi, apapun model atau pola kemitraan yang diterapkan, sebaiknya lebih ditekankan kepada orientasi pasar, bukan hanya orientasi produk.

\section{Bibliography}

Ali Mutasowifin. "Penerapan Balanced Scorecard Sebagai Tolok Ukur Penilaian Pada Badan Usaha Berbentuk Koperasi", Jakarta: Jurnal Universitas Paramadina, Vol. I No. 3, Mei 2002.

Felix Jebarus. 1997. “Balanced Scorecard dan Pengukuran Kinerja Bisnis”. Jakarta: Usahawan.

Herman Sòewardi. 1995. Filsafat Koperasi atau Cooperativism, Bandung: UPT Penerbitan IKOPIN.

Ulul Albab, Vol. 4 No. 1, 2003 
Kaplan, Robert and David P. Norton. 1996. Translating Strategy Into Action The Balanced Scorecard. Boston: Harvard Business School.

Muryati Sudibyo. 1997. “Koperasi Bukan Menyaingi Kelompok Jimbaran”. Jakarta: Usahawan.

Remitjahari. "Keadaan, Permasalahan dan Program Koperasi, Usaha Kecil dan Menengah di Jawa Barat", Makalah, dipresentasikan dalam Seminar Perekonomian "Mewujudkan Usaha Kecil Menengah Serta Koperasi Melalui Kemitraan Usaha Dalam Rangka Membangun Ekonomi Kerakyatan" di IKOPIN Bandung, 8 Mei 2002.

Rusidi dan Maman Suratman, ed. 2002. Bunga Rampai 20 Pokok Pemikiran Tentang Pembangunan Koperasi, Bandung: IKOPIN.

Sutyastie Soemitro Remi .2002. Profil Koperasi di Jowa Barat. Bandung: Dinas UKM Jawa Barat - Puslit Lembaga Penelitian Universitas Padjadjaran.

Soetjipto. 1997. "Mengukur Kinerja Bisnis dengan Balanced Scorecard”. Jakarta: Usahawan.

Thee Kian Wie. 1992. Dialog Kemitraan dan keterkaitan Usaha Besar dan Kecil Dalam Sektor Industri Pengolahan. Jakarta: Gramedia.

Yuyun Wirasasmita. "Penemuan Kembali (Reinventing) Kaidah-kaidah Koperasi dalam Menghadapi Perdagangan Bebas". Value FMK (Jurnal Ilmiah Manajemen Keuangan IKOPIN Bandung, Vo. I, 2000.

Varian, Hal R. 1999: Intermediate Microeconomics, a Modern Approach, New York, London: W.W. Norton \& Company, Fifth Edition. 